\title{
Scientific Basis of the Strategy of Holistic Sustainable Development of an Individual, Nation, Civilization
}

\author{
Nikolay Suvorov $^{1}$ and Irina Suvorova ${ }^{2}$
}

\begin{abstract}
The twentieth century was full of many crises and crisis events in various areas of people's lives. There were crises in science, in particular, physics. There were inter-ethnic, economic, political, financial, social crises, which entailed wars and revolutions. Politicians, sociologists explain, for various reasons and factors, the abundance of crises of the 20th century. But in essence, all crises were the result of the most important crisis of the spiritual, mental and moral crisis, the crisis of consciousness, the soul of an individual.

The modern era is characterized by an ecological crisis, a crisis of culture, a crisis of generations of people, a crisis of upbringing, and many, many other crises. At present, all the crises brought mankind to the brink of nuclear and environmental catastrophes.

The essence, causes of the emergence of a spiritual crisis, as well as ways out of it to form the scientific foundations of the strategy of holistic sustainable development of an individual, nation, and civilization are considered.
\end{abstract}

Key words: harmony-peace, harmony-love, innovative, cardinal transformation, metamorphosis.

\section{Introduction}

Nickolay Suvorov's book "Man of the Future. A $\rho i \sigma \tau o \varsigma \alpha \nu \theta \rho \omega \pi o \varsigma-$ The Perfect Man” was published by International Publishing E.RA., Moscow-Israel, in 2014. Book size is 304 pages. [1].

Fundamental, key concept of the book is harmony. On the basis of harmony, the criteria of perfection are established and the essence of a perfect man, a perfect society, a perfect state is defined.

From the standpoint of harmony, the essence of the most important words for a man: peace (harmony, balance), love, ethics and morality is considered.

Considering the exceptional importance of harmony, the mathematical foundations of the theory of harmony is developed. A quantitative measure of the harmony of simple and complex energy information systems of various nature, including anthropological structures and systems, is determined.

The scientific results obtained allowed to substantiate the strategy of the holistic sustainable development of A Nan and Mankind in the Modern Epoch. A set of scientific articles of the authors is devoted to this topic published in the European Journal of Sustainable Development (Rome, Italy) (2015 - 2018). ISSN: 2239-5938 [2 - 7]. 
It is proved mathematically that the preservation and development of a man, a nation, a civilization based on a rigorous and strict compliance with the two highest laws of the universe and the cosmos as a whole: ethics law;

- the law of harmony of the CREATOR, the law of harmony-peace, the highest

- the law of harmony of GOD, the law of harmony-love, the highest morality law [7].

The cause of many different diseases, misfortunes, anguish, suffering of an individual is a decrease in the quality of the energy of internal and external interaction, caused by a violation of the internal and external harmony of people.

Disturbance of harmony is a consequence of distorted thinking, wrong world view, ignorance of the HIGHER LAWS of the CREATOR AND GOD of HARMONY.

By correcting the thinking and worldview, an individual can increase the mental and physical stability of the body, provide high immunity and resistance, get rid of all the negative problems.

The purpose and meaning of human life was determined by GOD. It is necessary to create innovative technologies and energies worthy of the CREATOR and GOD.

\section{About the purpose and meaning of life}

Knowledge of what things should be characterizes an intelligent person; knowledge of what things really are, characterizes an experienced person; knowledge as to how to change them for the better characterizes the human genius.

Denis Diderot

It is known that any scientific study begins with an explanation of the objective function. This is an axiom of research.

The renewed mind, striving for perfection, must inevitably formulate the question: what is the purpose and meaning of human life?

CREATOR defined the role, function, purpose and meaning of human life: "... man does not live to drink, eat and multiply, but drinks, eats and multiplies in order to know himself, his divine principle, learn the process of creation, become my assistant and co-creator "[8]. This is the ultimate goal of human development.

Since a person lives on a particular planet in a particular galaxy, in a particular universe of the World abode of God, the important intermediate goal of human life, the stage of its evolution to become a long-term assistant and co-creator with God.

Thus, the purpose and meaning of human life is the creation, constructing on the basis of constant, permanent improvement and self-improvement.

There are many universes, there are Supreme Beings who create universes and they constantly monitor and correct the activities of these created universes.

The target setup of the CREATOR in the human language is formulated simply as: there is a need in order to live, but not to live in order to eat. Unfortunately, too many people see the purpose and meaning of life in food, sex, alcohol, drugs and other similar 
pleasures. More "sublime" part of people rushed to the money, power and material contentment. In this case, there is a bias, an imbalance, a violation of the measure in the direction of the external material to the detriment of the inner spiritual. Desires, worldly passions are brought to an unacceptable limit of absurdity. An individual makes himself a slave of desires, passions. Violation of measures has become the norm of life habit. All this is rooted not only in the mind, but also in the subconscious of people. Unrestrained striving for comfort, luxury, pleasure is justified by the natural course of the development of civilization.

Of course, you cannot stand up for cave life. An individual is worthy of luxurious living conditions, enjoying the highest benefits of civilization. Creating new attributes of civilization is also a stimulus for the development of science, technology, economics, and, consequently, for the development of society, an individual. However, even the ancients understood better than we did that the development of civilization is not only the creation of new material values, but also the creation of spiritual values. Civilization and culture are two sides of the same coin.

The Greek word $O \pi O \lambda \iota \tau \iota \sigma \mu \rho \zeta$ (politizmos) many values - it is a civilization (tangible assets) and culture (intellectual, spiritual values). The concepts of civilization and culture are inseparable. This is a single inseparable whole; they must be coordinated among themselves and developed in harmony. Gap, separation of civilization from culture is unacceptable, inadmissible bias, imbalance, disharmony between civilization and culture, the lag of cultural development from the development of civilization is unacceptable. It is unacceptable, absurdly, when the "cart" is ahead of "horse" when the "cart" has priority when it operates "a horse." Spiritual and mental values should take precedence over material ones. The first form and determine the balance, harmony in the overall process of development of the values of society and an individual. So it should be ideally. The state and society cannot be normal; they ignore not only the priority, but the development of the space of mind and spirit, or replace this development with declarative statements.

The modern concept of the essence of civilization is identical to pragmatism.

If you do not establish the harmony between the spiritual and the material, then civilization will necessarily degrade, it will go down to pragmatism. The pragmatism of the West convinces us of the validity of this statement.

My desires above all are the philosophy of pragmatism. The main thing in life is me $-\varepsilon \gamma \omega$ (ego). Pragmatism always exists along with egoism, they are inseparable.

It makes sense to introduce a generalized word egopragmatik, egopragmatizm. These generalized words define, in a single whole, the qualities of an egoist and a pragmatist. Egopragmatiks, as a rule, reject everything that is necessary for the development of a common, whole. Selfishness, supported by pragmatism, is the antithesis of collectivism. Egopragmatiks are too far to understand the significance and strength of the collective, the collective mind. The categories of harmony are likemindedness, unanimity is not for egopragmatiks. Egopragmatism is an aspiration for the elementary, primitive; it is, as a rule, the negation of spiritual and moral values.

Pragmatism and egoism are accompanied by distortions:

- the purpose and meaning of human life; 
- the essence of the individual, personality;

- the essence of love;

- the content of morality and ethics.

Egopragmatism distorts, perverts God's purpose concerning man.

Egopragmatik simplifies the human world, creates a wrong way of life. The Egopragmatik is not able to understand or deliberately ignores the general principles of the development of the Universe, he contributes to the destruction of the physical plane in the World and creation in the Antiworld.

Egopragmatism creates disharmony, clogging, destruction of the physical, astral, mental body and soul. The result is premature illness and many problems in communication among people. Internal problems of human (health problems), external issues (human relations) have the same roots, the same nature, ignorance, lack of knowledge of the general laws of the universe, people, human laws of harmony. Egopragmatism is a manifestation of diabolism.

According to the divine destiny of man - not a consumer matter and exploiter of Nature and co-creator with God. The purpose and meaning of human life is creation, making, continuous improvement and self-improvement based on the maximization of harmony.

To become a co-creator, it is necessary to form a correct worldview. The correct worldview requires the development of cosmotheory - the theory of the development of the Cosmos- Universe (the Universe and people).

\section{Intuitive apprehensions of changes}

There are many things in the world, friend Horatio, which was not the dream of our sages.

William Shakespeare

European security depends on and is determined by a scientifically based strategy for its development. In turn, a strategy, in particular, a strategy of holistic sustainable development cannot be developed without a scientifically based philosophy, main concepts and principles of development.

However, the philosophy of sustainable development also cannot be justified without a clear and precise understanding of the essence and principles of development - the evolution of man, the whole of society, forming the economy, politics and all superstructures.

Everywhere and in everything the most important thing is an individual, people. Therefore, the scientific substantiation of the strategy of development-evolution of an individual, self-improvement and improvement of people, the formation of a high quality of an individual personality is paramount. The study of the quality of a personality is possible and expediently carried out on the basis of an analysis of the quantity and quality of energy, self-energy, energy of internal and external interaction.

The study of energy, knowledge of the possibilities of controlling the quantity and quality of energy of energy-informational and energetic entities, structures and systems of various natures is a problem of tremendous complexity and importance. 
Energy, power quality is important to know, there and everywhere, in all kinds of formation and transformation of energy. The progress of the economy, the development of new technologies, is ultimately determined by the knowledge of the principles of energy quantity and quality management. Therefore, it is logical and natural to study various simple and complex entities, structures and systems is the energyinformation approach.

The energy quality indicator, first of all, is important for analyzing the methods of forming a new individual, society, nation, methods of improvement - upbringing, training of homo sapiens.

For the first time in Europe and the World, it is scientifically substantiated and proved that harmony is a universal criterion for the quality of interaction energy, optimality and perfection of complex energy-information and energy structures and systems of various natures. A mathematical interpretation of harmony has been developed; a quantitative measure of harmony has been defined. The scientific substantiation of harmony can make revolutionary changes in many areas of human activity.

At the end of September 1999, the 4th Fiction Congress was held in St. Petersburg. Writers around the world competed in creating "pictures of the future". One of the famous science fiction writers, Robert Sheckley, predicted a wonderful future: "I think the most important thing that awaits us in the future is a significant shift in values and a change of convictions. I think that after some time, power and strength will become not the most important factors human life. The main aspiration of people will be the development of themselves as individuals. The idea of personal improvement of the soul will be more important for humanity than anything else".

We know science fiction writer Jules Verne. In the twentieth century, the fantasies described in his novels became a reality.

Another colorful premonition of change is made by Dm. Vereshchagin:

"Now many people like to talk about the approaching end of the world. However, there is every reason to assume that the outlined end of the world has already been canceled. Why? Because humanity was not at all hopeless. In the face of the abyss, its individual representatives suddenly saw the light and thought better of it. As a result, here and there, still not very noticeable and rather slowly, but already noticeably, sprouts of a new humanity appear - gradually, as the grass through the asphalt, they make their way. Together with them, hope breaks the road for the survival of the human community. Here and there, there are people, due to which humanity will survive "[9].

The intuitive presentiments of the changes of man and humanity are beautiful, but they are not yet constructive or not constructive enough.

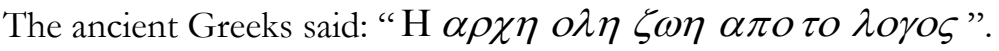

This means that the foundation, the primary source of all life is LOGOS. LOGOS is a word, but LOGOS, first of all, means the mind, the ability to think.

At the present stage of human and human development, LOGOS sets, on the one hand, the task of popularizing the Word of God, and on the other, the more complex problem of the synthesis of science, philosophy, religion into a single theory about Man and for Man. 
Science, philosophy, religion is important for knowing, determining the path or vector of movement of an individual to God. God is understood as an idealized interpretation of the Higher Mind.

But each of the components of our knowledge science, philosophy and religion separately is currently imperfect. The way of life of a modern person is proof and confirmation of this.

In ancient times, the scientific and religious knowledge of the world were united. From religion evolved and became independent science, philosophy, all kinds of art. At present, the best representatives of science have understood the need for the formation of a union of science and religion, hoping that such a union will be able to help humanity out of the most important, namely, moral crisis, in which civilization finds itself. However, we know that even the most monolithic, "unbreakable" union can be destroyed if there is no objectively correct idea of unity. Consequently, the idea should be formulated of forming not a union, but harmony, an organic, indissoluble fusion of science and religion.

On the basis of harmony and fusion of the latest achievements of science, philosophy and religion can be formed by a single coherent doctrine of Man and for Man - Cosmic theory.

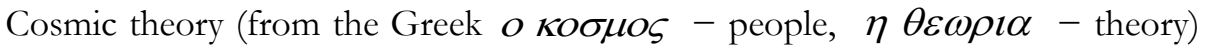
- people theory aims to form:

- perfect man, $\alpha \rho i \sigma \tau o \varsigma \alpha v \theta \rho \omega \pi o \varsigma$ - aristos anthropos ( $\alpha \rho \imath \sigma \tau o \varsigma$ - perfect,

o $\alpha v \theta \rho \omega \pi o \varsigma-\operatorname{man})$

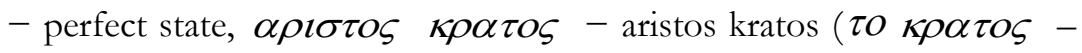
state);

- perfect society, $\eta \alpha \rho \imath \sigma \tau о \kappa \rho \alpha \tau \iota \alpha-$ aristocracy.

Creating cosmic theory is a problem not only of great importance, but also of complexity. In the real case, at the present level of development, one can speak only of cosmic theory concepts.

Harmony, quantitative assessment of harmony - the most important values, presented to us by God.

Harmony is the Great Cosmic Law of Development, the Law of God, the basic principle and technology of creation.

Harmony is a criterion of optimality, perfection and high quality of the energy of interaction in energy information systems of various natures.

This is enough to bring about radical changes in a diverse human life.

\section{Conclusion}

Thus, a foundation was developed for the formation of a New Age of An Individual. A qualitatively new level of development of homo sapiens has been developed - its innovative, cardinal transformation, metamorphosis. 
It is advisable to train a perfect individual in the Scientific and Training Center of the Sustainable Development of the Nation and Civilization. To work in such a Center, one should attract the best minds of mankind - the luminaries of science.

\section{References}

1.Suvorov N.P. A $\rho \imath \sigma \tau O \varsigma \alpha v \theta \rho \omega \pi O \varsigma$ - Perfect Man. - M.: E.RA, 2014. - 304 pp.

2. Nikolay Suvorov and Irina Suvorova. Scientific basics of forming human quality and perfection to ensure holistic sustained development. European Journal of Sustainable Development (2015), 4, 1, 149 160. Doi: $10.14207 /$ ejsd.2015.v4n1p149. ISSN: 2239-5938.

3. Nikolay Suvorov and Irina Suvorova. The Concept of Holistic and Sustainable Development Based on Harmony. European Journal of Sustainable Development (2015), 4, 2, 227-234. Doi: 10.14207/ejsd.2015.v4n2p227. ISSN: 2239-5938.

4. Nikolay Suvorov and Irina Suvorova. Peace, Love, Harmony and Perfection are the Basic Components of Holistic Sustainable Development of the Nations and Civilisation. European Journal of Sustainable Development (2016), 5, 3, 383-396. Doi: 10.14207/ejsd.2016.v5n3p383. ISSN: 22395938.

5. Nikolay Suvorov and Irina Suvorova. The Switzerland Phenomenon - An Example of Sustainable Development of a Nation. European Journal of Sustainable Development (2017), 6, 3, 61-68. Doi: 10.14207/ejsd.2017.v6n3p61. ISSN: 2239-5938.

6. Nikolay Suvorov and Irina Suvorova. Scientific Substantiation of the Development-Evolution of New Man Founded on High-Quality Interaction Energy Created by Using Harmony, Ethical Canons and Holistic Principles. European Journal of Sustainable Development (2017), 6, 4, 531-537. Doi: 10.14207/ejsd.2017.v6n4p531. ISSN: 2239-5938.

7. Nikolay Suvorov and Irina Suvorova. Discovering the Mathematical Formula of the Universal Law of Harmony of the CREATOR and the Law of Harmony of GOD to Ensure a Holistic Sustainable Development of Man and Humanity. European Journal of Sustainable Development (2018), 7, 2, 81-88. Doi: 10.14207/ejsd.2018.v7n2p81. ISSN: 2239-5938.

8. Sadetsky TA, VA Sadetsky Great Fire Galaxy And We. - M.: Zhoalino, White Alva, 1997. - 656p.

9. Dmitry Vereshchagin: Maturity. The power of your soul. - St. Petersburg: Nevsky Prospect, Series: System DEIR, 2000. - 160 p. (In Russian). ISBN: 5-8378-0018-2. 